\title{
INFLUENCE OF CARBON FibERS ON MECHANICAL PROPERTIES OF MATERIALS IN FDM TECHNOLOGY
}

\author{
Damir Hodzic \& Adi Pandzic
}
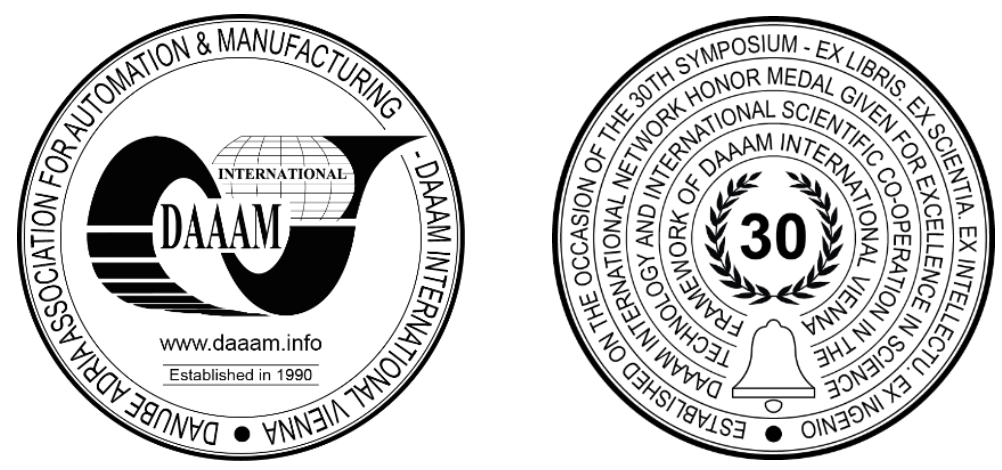

This Publication has to be referred as: Hodzic, D[amir] \& Pandzic, A[di] (2019). Influence of Carbon Fibers on Mechanical Properties of Materials in FDM Technology, Proceedings of the 30th DAAAM International Symposium, pp.0334-0342, B. Katalinic (Ed.), Published by DAAAM International, ISBN 978-3-902734-22-8, ISSN 1726-9679, Vienna, Austria

DOI: $10.2507 / 30$ th.daaam.proceedings.044

\begin{abstract}
While fused deposition modeling (FDM) is one of the most used additive manufacturing (AM)process today due to its ability to produce products with very complex geometries and with wide range of different thermoplastic materials. Engineers have the option of making parts with the most commonly used thermoplastics, such as ABS, PLA, PET-G, a variety of blends, as well as engineered thermoplastics for aerospace, medical, automotive, electronic and other specialty applications. The aim of this paper is to investigate tensile properties of carbon reinforced PLA and carbon reinforced PET-G materials, and make a comparison of carbon PLA with PLA and carbon PET-G with PET-G material. For every material it will be tested 2 specimens with different $3 \mathrm{D}$ printing orientation angle $\left(0^{\circ}, 15^{\circ}, 30^{\circ}\right.$ and $\left.45^{\circ}\right)$ prepared according to ISO 527-2. Specimens would be 3D printed on Ultimaker $2+$ with steel nozzle and under the same conditions of 3D printing, in order to reduce impact of unwanted factors on material tensile properties. The results of this paper will be useful to see whether it is profitable to use carbon-reinforced materials and whether they really increase the tensile properties of basic materials.
\end{abstract}

Keywords: Carbon; PLA; PET-G; FDM; 3D Print.

\section{Introduction}

Additive manufacturing (AM) is an emerging manufacturing technique that has opened up new opportunities for producing complex functional structures without the need for any tooling. In the ASTM standard, AM is defined as ,,a process of joining materials to make objects from 3D-model data, usually layer upon layer, as opposed to subtractive manufacturing methodologies. Synonyms: additive fabrication, additive processes, additive techniques, additive layer manufacturing, layer manufacturing and freeform fabrication". For increase of industrial competitiveness and rapid market entry with new products, various additive technologies are increasingly being used today. In the world market, a large number of additive technologies have been implemented, which are primarily distinguished by the method of layer construction (photopolymerization, extrusion and solidification, bonding, laminating, etc.) [1], [2].

The most frequently used type of AM technology is Fused Deposition Modeling (FDM) due to its low cost and easy application. It is an extrusion-based additive technology. In FDM process, a thermoplastic filament is fed into a liquefier using a pinch roller mechanism and feedstock is melted in a temperature controlled liquefier as shown in Fig. 1. The incoming filament acrs as a piston to push the melt through a print nozzle whose diameter is in the order of a few 
millimeters. A support control system moves the nozzle in the $x-y$ plane as the material is deposited on a build surface. The material is added layer-by-layer in $\mathrm{Z}$ axis direction. The movement commands and printing parameters are provided by a G-code file, made with a CAM or slicer program [3], [4], [5].

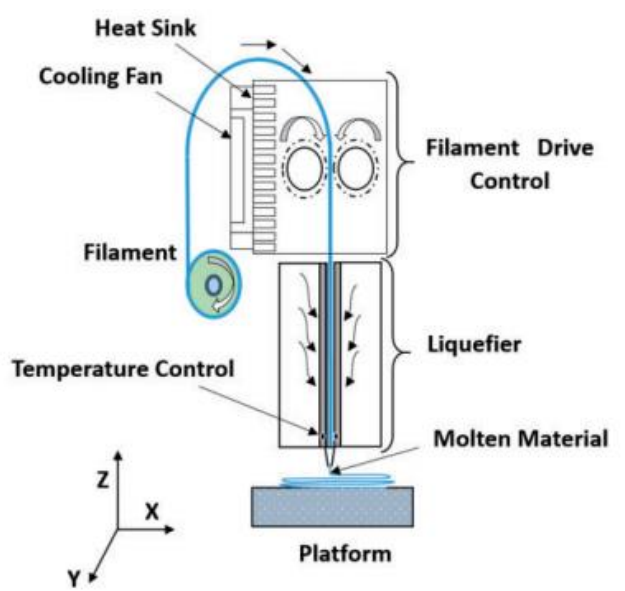

Fig. 1. Schematic of FDM technology process [5]

Today in general FDM process is primarily used in education and prototype assembly, but also it is widely used in engineering such as automotive and aerospace industry, but also in field of architecture, bioengineering, medical equipment, prosthetic parts, fixtures and more. Consequently, designers must understand how these 3D printed products behave when subjected to mechanical loads and they must evaluate their adequacy for a given application [6], [7], [8].

FDM is a relatively complex and highly flexible process with many parameters that affect mechanical and qualityrelated properties of product, and some of them are presented on Fig. 2. Therefore, it is important to investigate and study the mechanical properties and behavior of FDM for different categories of materials and sets of process parameters/manufacturing conditions [6], [9], [10], [11].

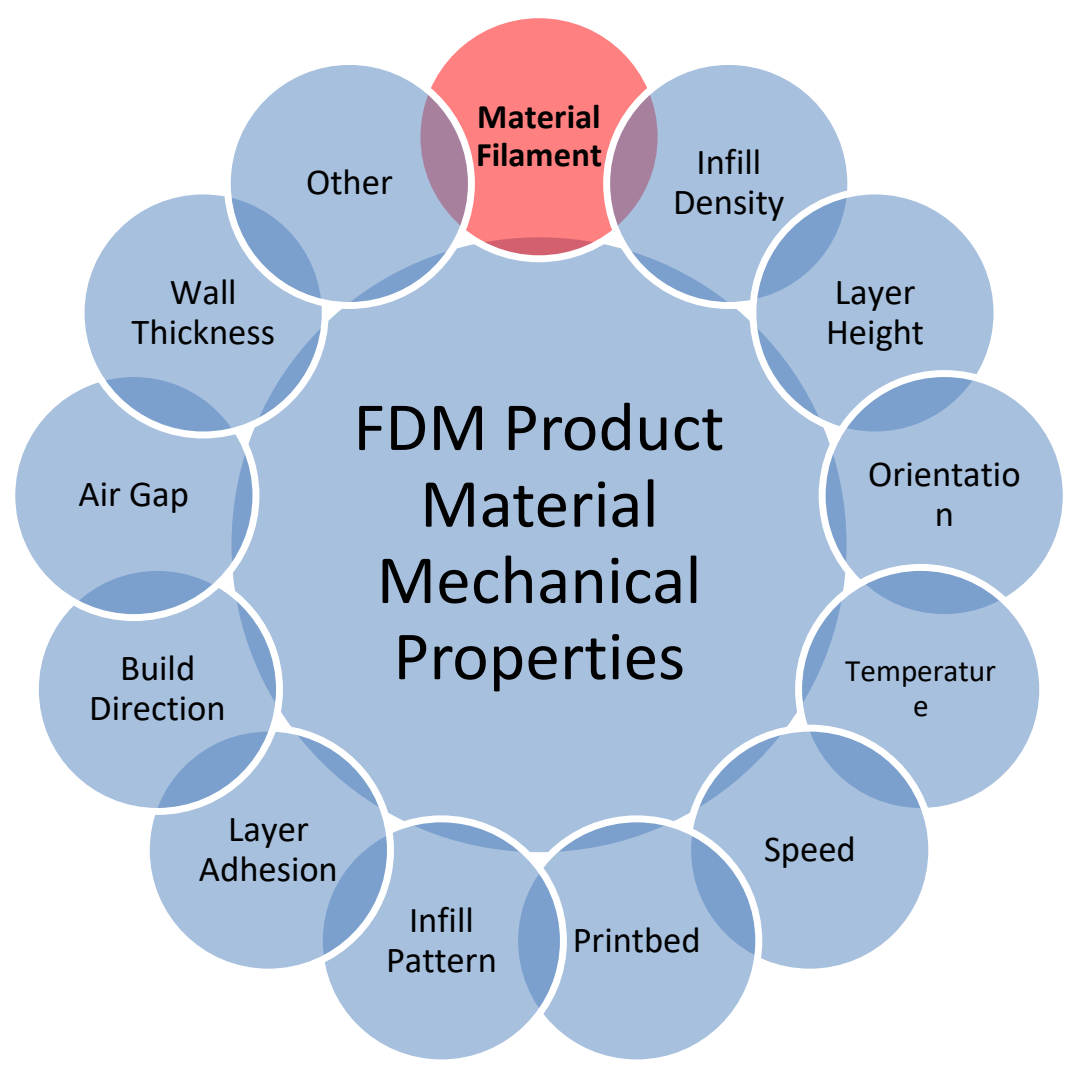

Fig. 2. Parameters that influence on 3D printed material mechanical properties

3D printing material is the material basis of 3D printing, which is also a technical bottleneck to develop 3D printing further. At present, the raw materials suitable for FDM are only thermoplastic wire. Various thermoplastics are currently used to produce parts satisfactorily by FDM. Among them are polylactic acid (PLA), acrylonitrile butadiene styrene 
(ABS), poly-carbonate (PC), polyethylene terephthalate glycol (PET-G) and more. The shortcomings of 3D printed parts with pure thermoplastics made by FDM are low mechanical properties (limiting their use in engineering applications), single function and weak carrying capacity. To overcome this problem, the addition of carbon fibers (CFs) in the polymer matrix could increase both tensile strength and Young's modulus to levels sufficient for new applications [12], [13].

This paper aims to investigate tensile properties of carbon reinforced PLA and carbon reinforced PET-G materials, and make a comparison of carbon PLA with PLA and carbon PET-G with PET-G material. Also to investigate whether it is profitable to use carbon-reinforced materials and whether they really increase and how much the tensile properties of basic materials.

\section{Materials}

Among the various AM techniques, the FDM is ranked as one of the most popular and widely used methods for manufacturing parts with plastic materials [13]. Today, there are many different thermoplastic materials for FDM on the market, and focus of this study is on PLA, PET-G, Carbon-P (PET-G with carbon fibers) and Carbon Fiber PLA materials.

PLA is a natural biopolymer, that means it is biodegradable and environmentally friendly [6]. PLA is the most extensively researched and utilized biodegradable thermoplastic and is considered one of the most promising biopolymers used for medical application thanks to a combination of high elastic modulus, low glass transition temperature of 55$65^{\circ} \mathrm{C}$, and suitability for 3D printing. Also PLA is a tough and easy to 3D print FDM material [13], [14].

PET-G is one of the most important engineering polymers because of its mechanical characteristic features (machinability, colorability etc). PET-G is better than other thermoplastics and it has strength, toughness, brightness, impact resistance, also its gas permeability is lower than most others [15].

PLA, PET-G and Carbon-P materials used in this study are produced by 3D Republika and CFPLA by Proto-pasta. All materials came with wire (filament) diameter of $2,85 \mathrm{~mm}$, and that is standard filament diameter size for Ultimakers 3D printers. Material properties from manufacturer used in this study are presented in Table 1, also manufacturer gave short description of every material as:

- $\quad$ PLA is a tough, easy to use high grade PLA type of filament, ideal for 3D printing. Slightly modified, the filament retains the typical features of PLA, but makes it tougher and less brittle. Due to a low shrinkage factor PLA will not deform after cooling. Poly Lactic Acid is a biodegradable plastic made from renewable natural resources and one of the most popular materials for 3D printing.

- $\quad$ Proto-Pasta Carbon Fiber Reinforced PLA filament provides fabulous structural strength and layer adhesion with very low warpage. Due to the carbon fiber that is in the filament, it contains increased rigidity, therefore it has increased structural support built right in. This filament is perfect for printing items that do not bend, such as: frames, supports, propellers, and tools. The carbon fiber in the filament is specifically designed to be small enough to fit through the nozzles, but long enough to provide the extra rigidity that makes this reinforced PLA so special. Printing with ProtoPasta Carbon Fiber PLA is very similar to printing in standard PLA - it does not require a heated bed. The carbon fiber can make the PLA a little more abrasive when extruding, meaning that prolonged use can increase wear on your 3D printer - especially on lower end nozzles.

- $\quad$ PET-G is a strong, high clarity, odor neutral and easy to print filament for 3D printing. These characteristics, together with the high impact strength, excellent flexibility and practically no shrinkage make PET-G an excellent material which combines the advantages of both PLA and ABS. The filament is hydrophobic and therefore does not absorb water. In short, PET-G has many great features and is the perfect addition to any filament assortment.

- CARBON-P is our $20 \%$ carbon fiber reinforced PET-G based filament. The result is a twice as stiff filament as PET-G with increased impact and heat resistance (HDT) to $80^{\circ} \mathrm{C}$. This, together with other features, such as a matt surface, no warp, dimensionally stable and extremely forgiving to print, makes CARBON-P suitable for a very wide variety of applications besides the typically mentioned RC parts, drones, automotive and more.

\begin{tabular}{|c|c|c|c|c|c|}
\hline \multicolumn{7}{|c|}{ Material properties } \\
\hline Description & Test method & PLA & CFPLA & PET-G & Carbon-P \\
\hline $\begin{array}{c}\text { Tensile strength at } \\
\text { yield [MPa] }\end{array}$ & ISO 527 & 70 & Not defined & 50 & 52,5 \\
\hline Strain at yield [\%] & ISO 527 & 5 & Not defined & 6 & Not defined \\
\hline Strain at break [\%] & ISO 527 & 20 & Not defined & 23 & Not defined \\
\hline E-Modulus [MPa] & ISO 527 & 3120 & Not defined & 2020 & 3800 \\
\hline $\begin{array}{c}\text { Impact strength - } \\
\text { Charpy method } 23^{\circ} \mathrm{C}\end{array}$ & ISO 179 & $3,4\left[\mathrm{~kJ} / \mathrm{m}^{2}\right]$ & Not defined & 8,1 & 3,8 \\
\hline Printing temp [ $\left.{ }^{\circ} \mathrm{C}\right]$ & DF & $205 \pm 10^{\circ} \mathrm{C}$ & $195-220^{\circ} \mathrm{C}$ & $240 \pm 10^{\circ} \mathrm{C}$ & $235 \pm 10^{\circ} \mathrm{C}$ \\
\hline Price & \multicolumn{7}{c}{$20 €$} & $28 €$ & $25 €$ & $32 €$ \\
\hline
\end{tabular}

Table 1. Manufacturer material properties 


\section{Experiment methodology}

The goal of this study is to analyse influence of carbon fibers on PLA and PET-G materials tensile properties. Schematic preview of experiment methodology is presented on Fig 3.

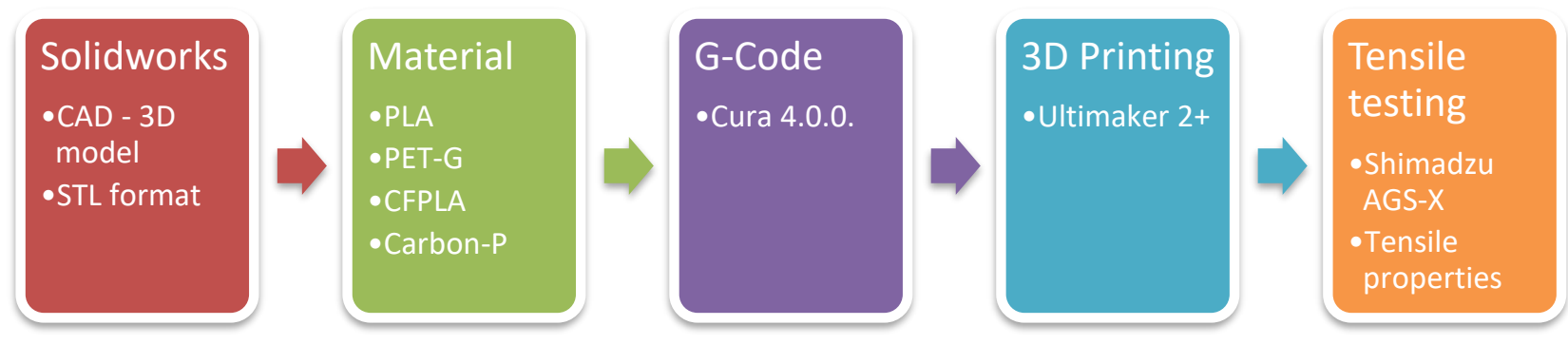

Fig. 3. Schematic preview of experiment methodology

For this experimental analysis 3D model of dogbone-type specimen is designed using Solidworks (software for 3D design). Dimensions of dogbone-type specimen are prepared according to ISO 527-2 standard, and presented on Fig. 4. Also Solidworks is used to create STL format of specimen 3D model, in order to make the specimen preparation for further $3 \mathrm{D}$ printing.
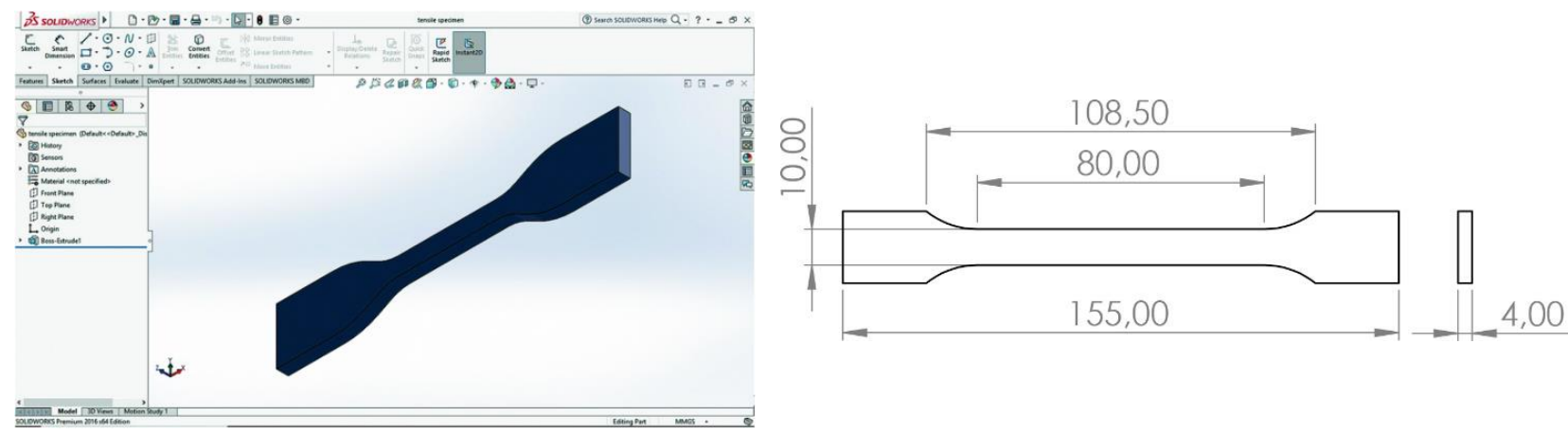

Fig. 4. Dogbone-type specimen according to ISO 527-2 standard

The Ultimaker 2+ 3D printer based on FDM principle was used to make specimens for testing. Slicing 3D model and preparation of G-code for printing is prepared using Ultimakers slicer software "Cura" version 4.0.0. Due to the abrasive properties of materials with carbon fibers, steel printing nozzle with diameter of $0,5 \mathrm{~mm}$ is used for printing of test specimens. Parameters for PLA and PET-G 3D printing are predefined with "normal profil" and for PLA and CPE materials in Cura slicer, but for CFPLA and Carbon-P some parameters have been modified and presented in table 2.

\begin{tabular}{|c|c|c|c|c|}
\hline \multicolumn{5}{|c|}{ 3D Printing parameters } \\
\hline Description & PLA & PET-G & CFPLA & Carbon-P \\
\hline Nozzle diameter & $0,5 \mathrm{~mm}$ & $0,5 \mathrm{~mm}$ & $0,5 \mathrm{~mm}$ & $0,5 \mathrm{~mm}$ \\
\hline Layer height & $0,15 \mathrm{~mm}$ & $0,15 \mathrm{~mm}$ & $0,15 \mathrm{~mm}$ & $0,15 \mathrm{~mm}$ \\
\hline Wall thickness & $0,7 \mathrm{~mm}$ & $0,7 \mathrm{~mm}$ & $0,7 \mathrm{~mm}$ & $0,7 \mathrm{~mm}$ \\
\hline Infill density & $100 \%$ & $100 \%$ & $100 \%$ & $100 \%$ \\
\hline Print speed & $60 \mathrm{~mm} / \mathrm{s}$ & $45 \mathrm{~mm} / \mathrm{s}$ & $60 \mathrm{~mm} / \mathrm{s}$ & $60 \mathrm{~mm} / \mathrm{s}$ \\
\hline Printing temperature & $200{ }^{\circ} \mathrm{C}$ & $240{ }^{\circ} \mathrm{C}$ & $210{ }^{\circ} \mathrm{C}$ & $230{ }^{\circ} \mathrm{C}$ \\
\hline $\begin{array}{c}\text { Build plate } \\
\text { temperature }\end{array}$ & $60{ }^{\circ} \mathrm{C}$ & $70{ }^{\circ} \mathrm{C}$ & $60{ }^{\circ} \mathrm{C}$ & $60{ }^{\circ} \mathrm{C}$ \\
\hline Fan Speed & $100 \%$ & $100 \%$ & $20 \%$ & $100 \%$ \\
\hline
\end{tabular}

Table 2. Main 3D printing parameters used for selected materials

Testing specimens are printed in "flat" printing position (Fig. 5). For every material, specimens are printed with different orientation angle $\left(0^{\circ}, 15^{\circ}, 30^{\circ}, 45^{\circ}\right)$, and for every orientation angle 2 specimens are printed. 

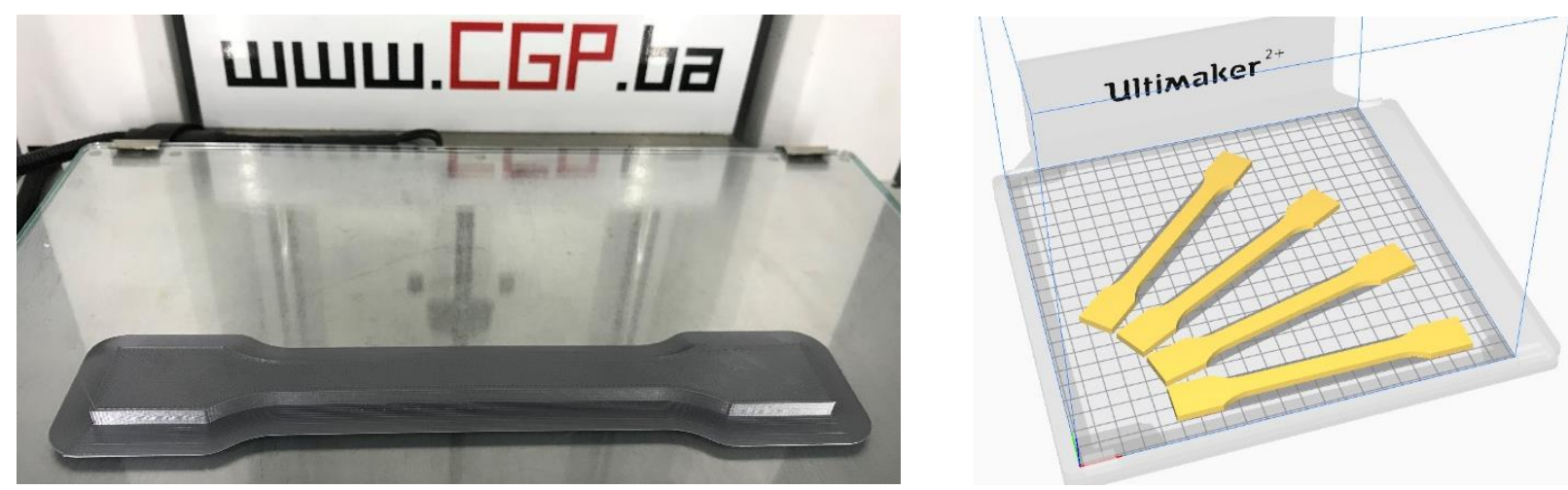

Fig. 5. Test specimens printed in "flat" position and with different orientation angle $\left(0^{\circ}, 15^{\circ}, 30^{\circ}, 45^{\circ}\right)$

Through this study, in the experimental part, mechanical tensile tests were carried out in order to test the tensile properties of PLA, CFPLA, PET-G and Carbon-p materials. Tensile tests were performed on these specimens using Shimadzu AGS-X tensile machine, with $100 \mathrm{kN}$ capacity. Specimens are examined according to ISO 527-2 standard, and with testing speed of $1 \mathrm{~mm} / \mathrm{min}$. The test results were recorded and the diagrams were plotted using Trapezium-X (Shimadzu Corp., Koyoto, Japan) software for tensile testing (Fig. 6).
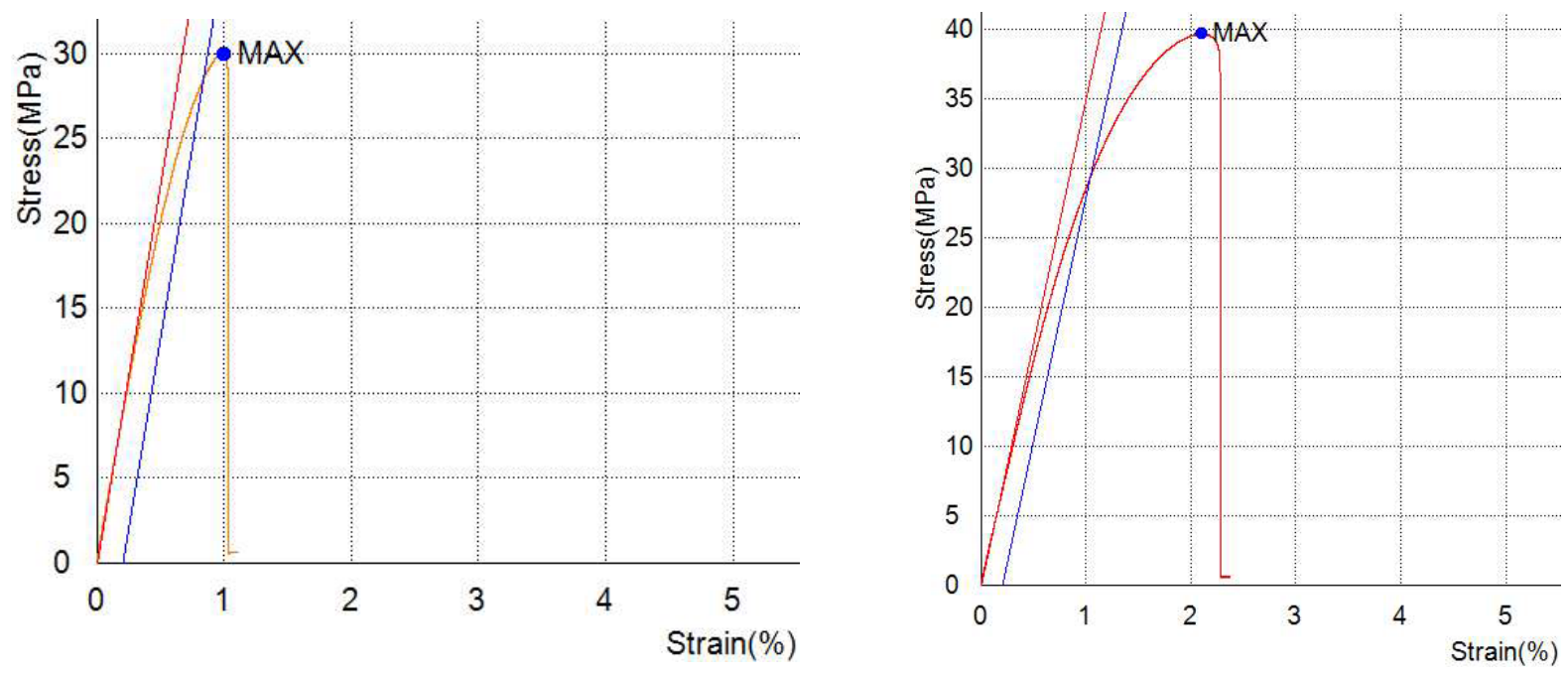

Fig. 6. Stress - Strain diagrams for CFPLA (left) and Carbon-P (right)

Specimens after tensile testing are presented on Fig. 7.
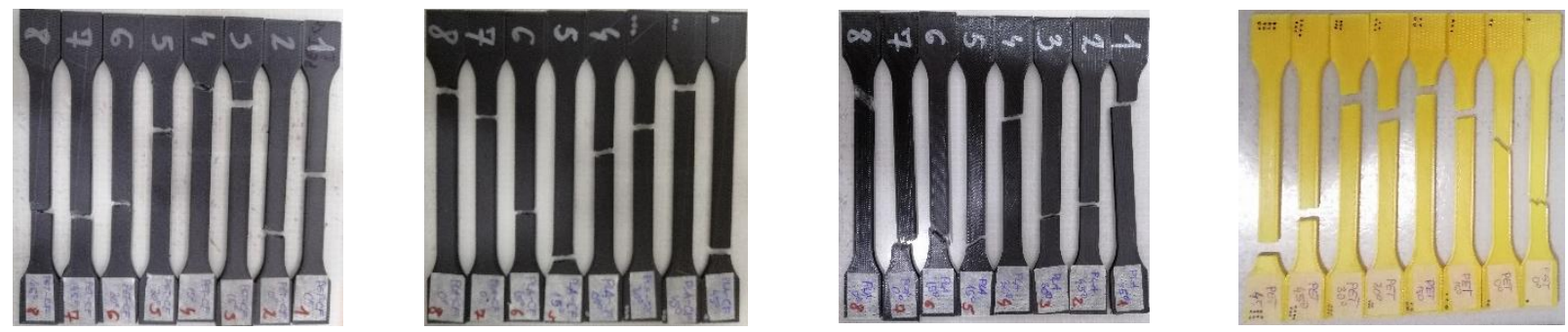

Fig. 7. Specimens after tensile testing (from left to right: Carbon-P, CFPLA, PLA and PET-G)

\section{Results and discussion}

After tensile testing, all results are collected and analysed in Excel. Influence of carbon fibers and 3D printing orientation angle on elastic modulus $(E)$, ultimate tensile strength $\left(\mathrm{R}_{\mathrm{M}}\right)$, yield strength $\left(\mathrm{R}_{02}\right)$ and strain $(\varepsilon)$ are presented bellow. 


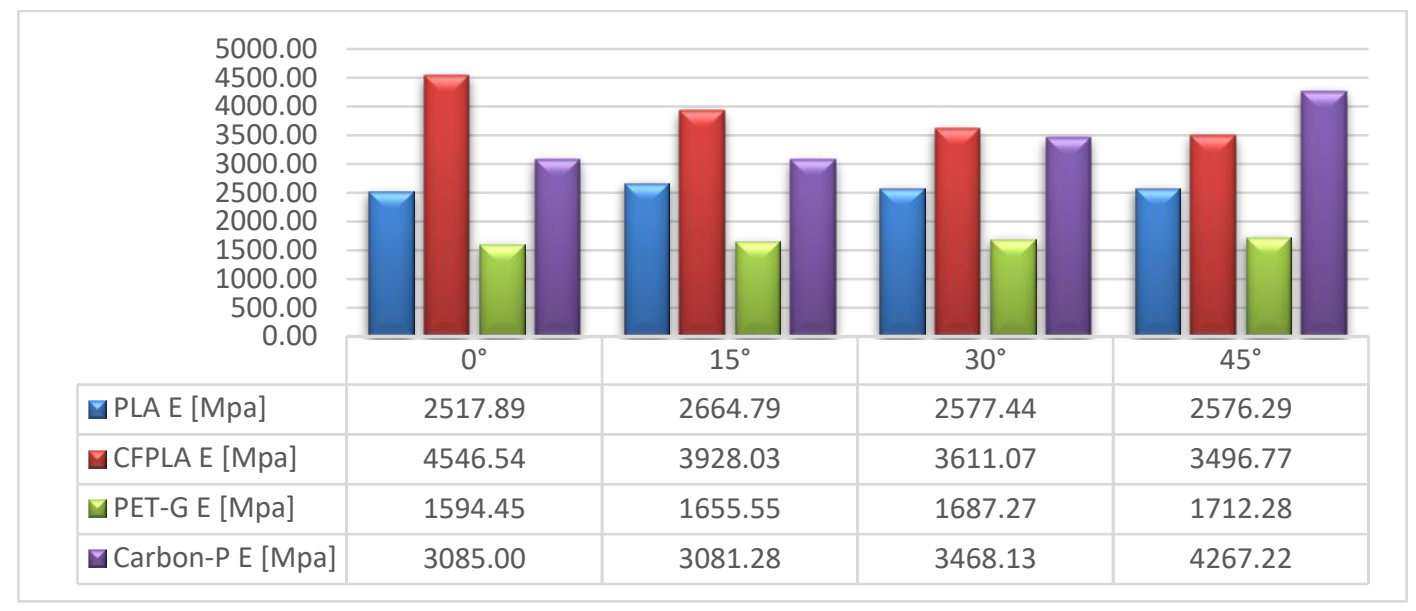

Fig. 8. Influence of carbon fibers and orientation angle on elastic modulus (E)

Analysing elastic modulus, it can be seen that carbon fibers increase elastic modulus in PLA and PET-G material. Carbon fibers in PLA increased elastic modulus for 50\% and in PET-G for 100\%. Material CFPLA with orientation angle $0^{\circ}$ and Carbon-P with orientation angle $45^{\circ}$ have highest elastic modulus.

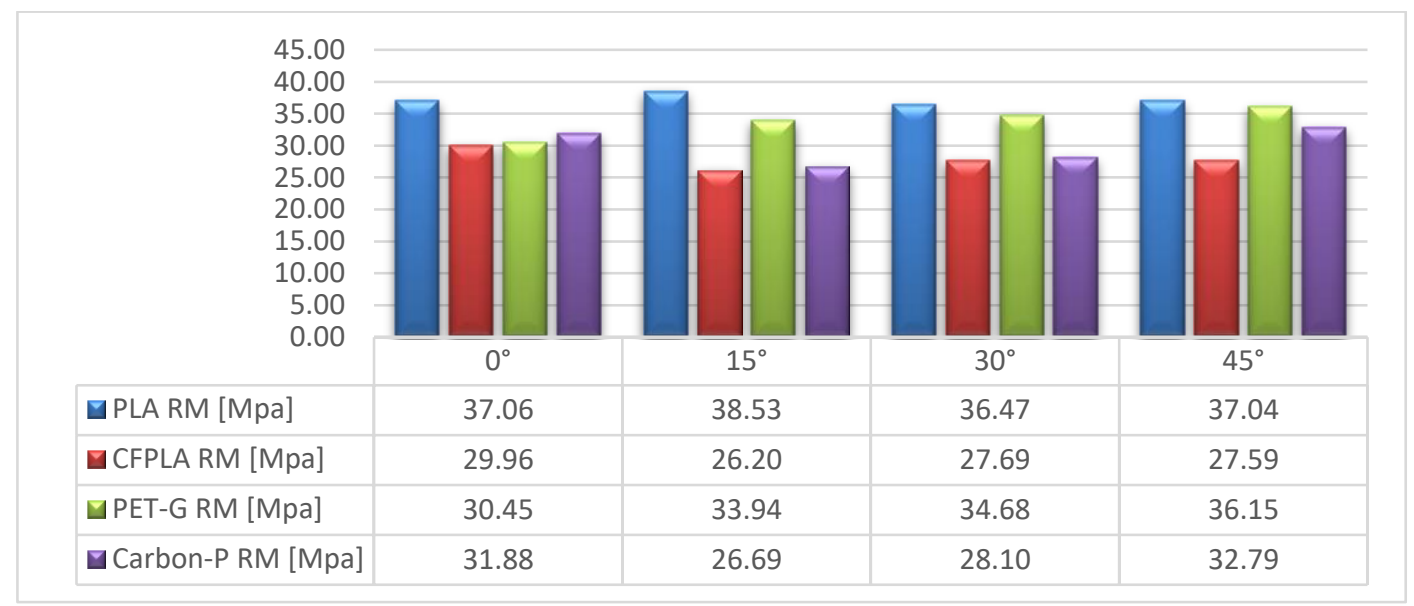

Fig. 9. Influence of carbon fibers and orientation angle on ultimate tensile strength $\left(\mathrm{R}_{\mathrm{M}}\right)$

From diagram above, it can be seen that carbon fibers decrease ultimate tensile strength for $27 \%$ in PLA and for $12 \%$ in PET-G material.

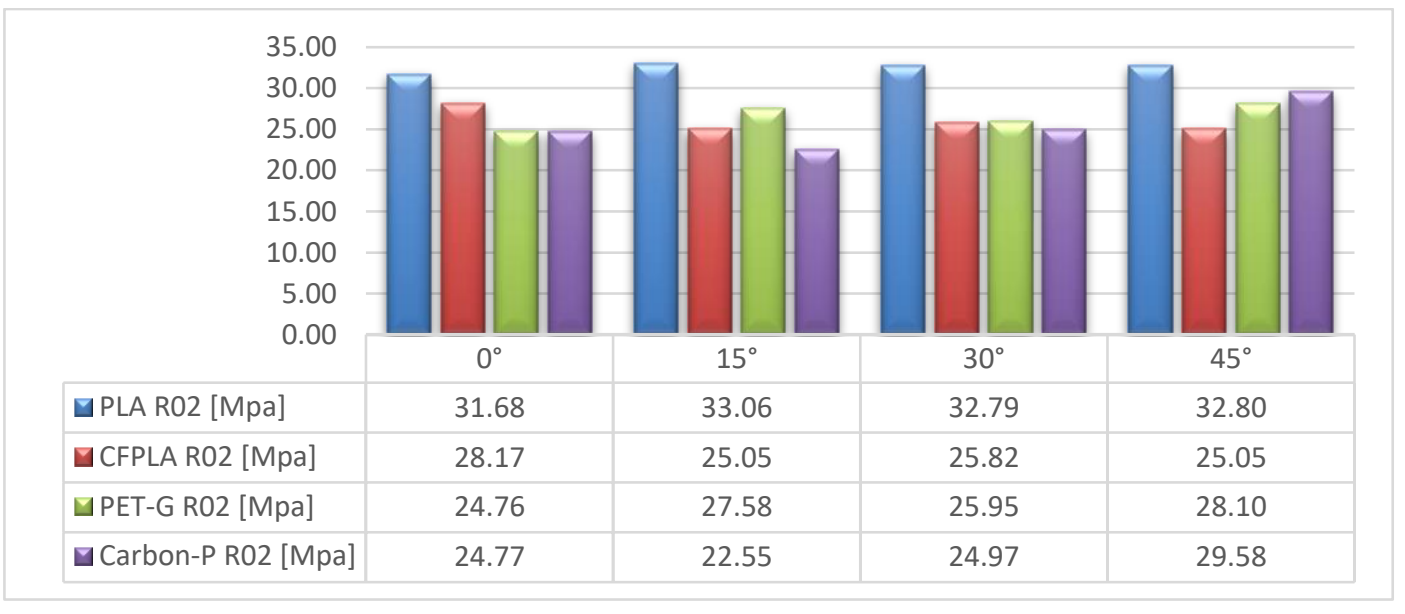

Fig. 10. Influence of carbon fibers and orientation angle on yield strength $\left(\mathrm{R}_{02}\right)$ 
Like ultimate tensile strength, carbon fibers also decrease yield strength. In PLA material carbon fibers decrease yield strength for $21 \%$ and in PET-G for $7 \%$.

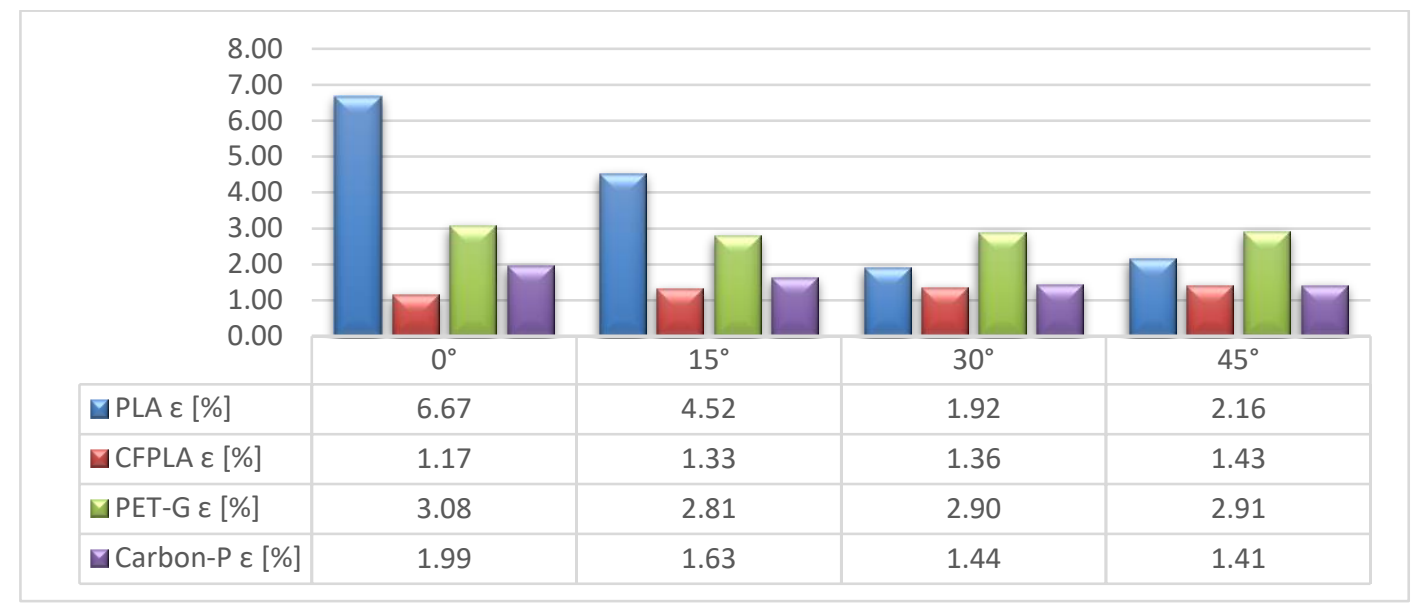

Fig. 11. Influence of carbon fibers and orientation angle on strain ( $(\varepsilon)$

Observing the strain its obvious that carbon fibers decrease it. In PLA material strain is decreased for $65 \%$ and in PET-G for $45 \%$.

In this study, toughness is also analysed. Software Trapezium-X calculating toughness over the surface under the Hook curve. Influence of carbon fibers and orientation angle on toughness is presented in Fig. 11.

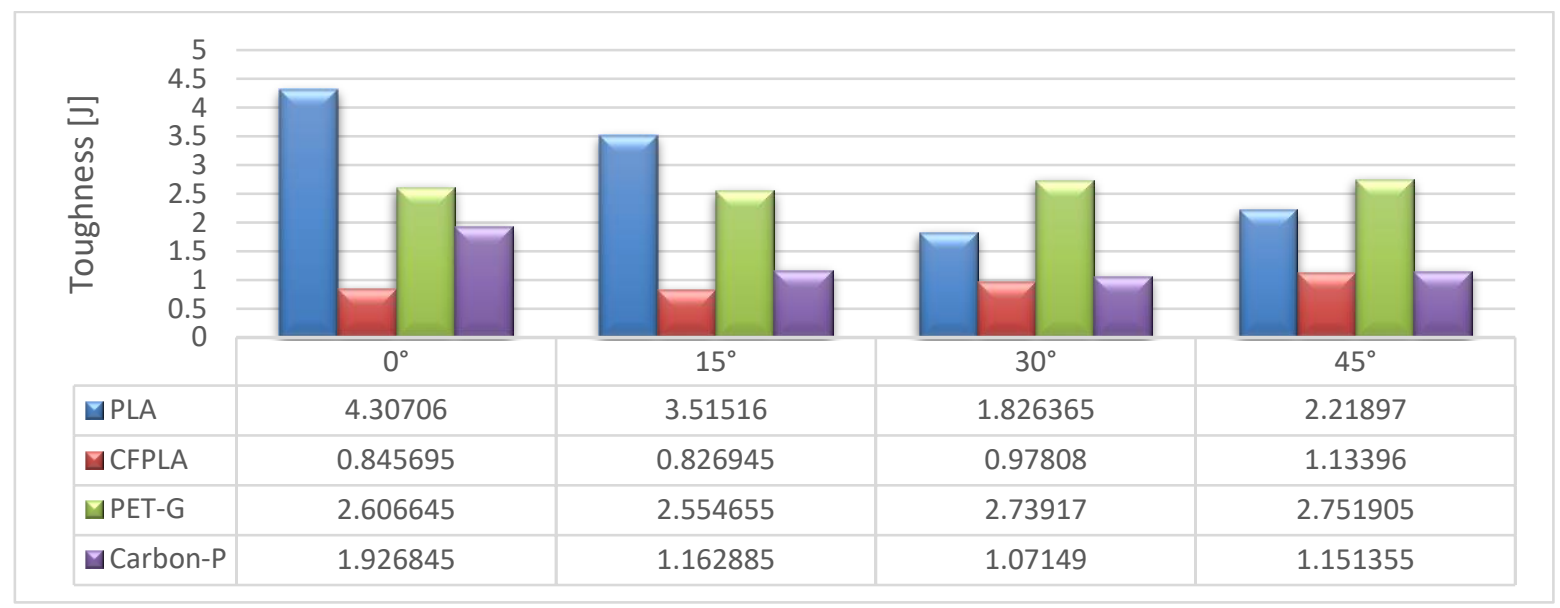

Fig. 12. Influence of carbon fibers and orientation angle on toughness

Analysing the toughness, it can be seen that carbon fibers decrease toughness in PLA material for $68 \%$ and in PET-G material for $50 \%$.
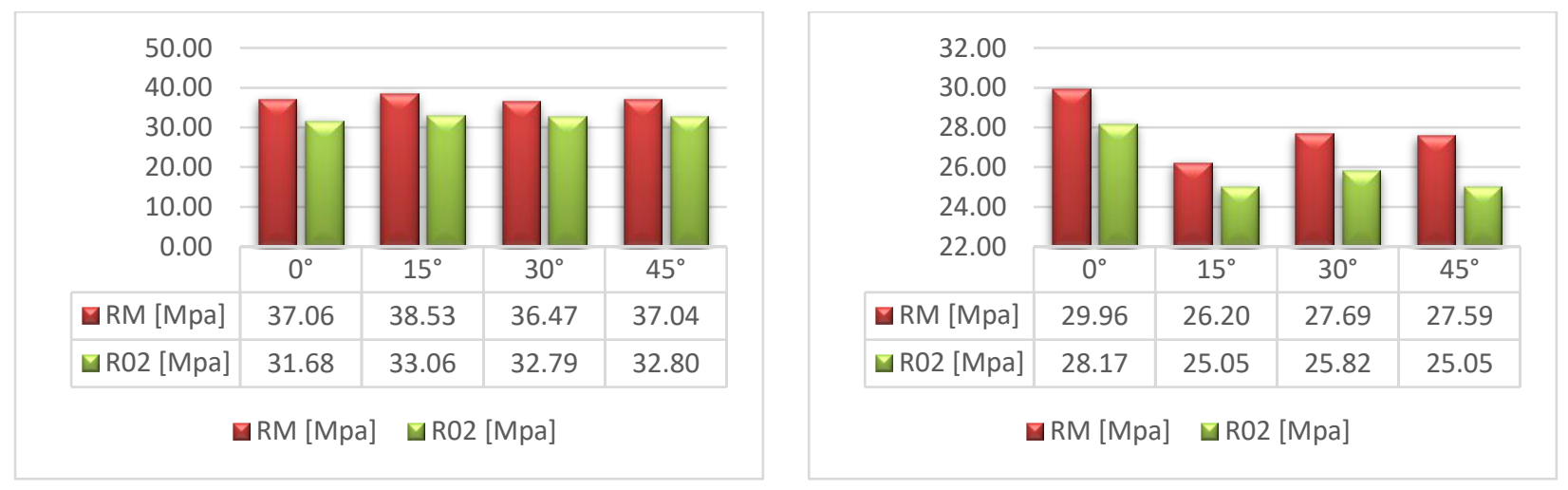

Fig. 13. Influence of 3D printing orientation angle on $R_{M}$ and $R_{02}$ in PLA and CFPLA materials 
3D printing orientation angle has no significant effect on ultimate tensile and yield strength in PLA material, but in CFPLA material, where there were carbon fibers, it can be seen (Fig. 13.) that orientation angle have influence on ultimate tensile and yield strength up to $10 \%$.
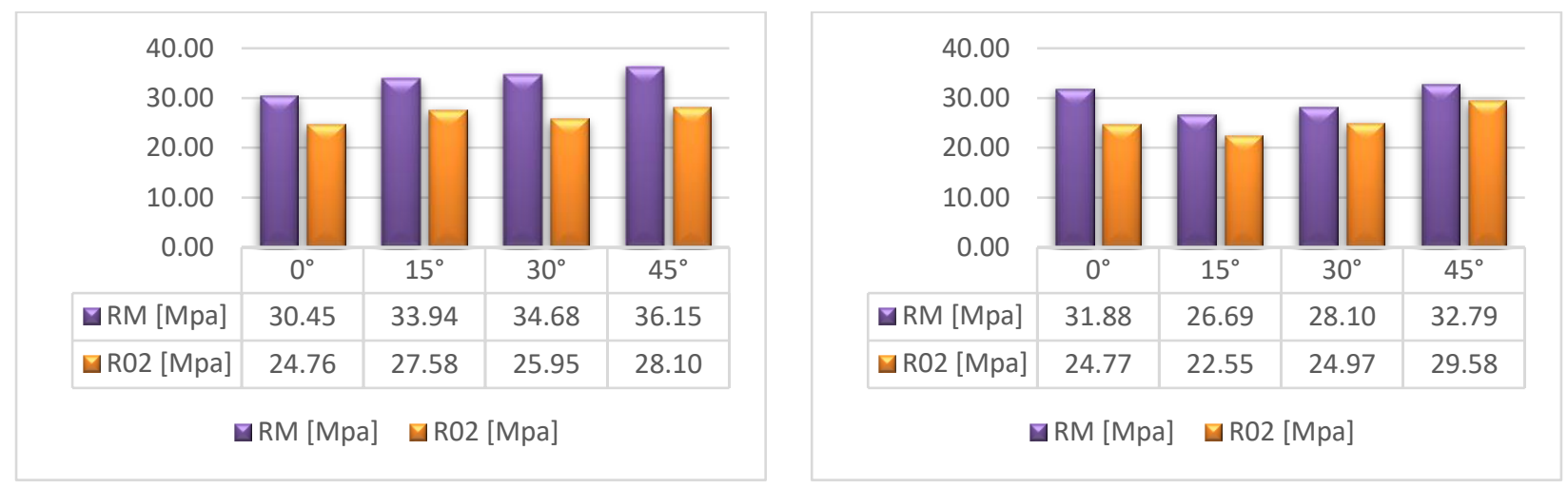

Fig. 14. Influence of 3D printing orientation angle on $\mathrm{R}_{M}$ and $\mathrm{R}_{02}$ in PET-G and Carbon-P materials

3D printing orientation angle have influence on ultimate tensile strength and yield strength in PET-G and Carbon-P materials, and it is up to $20 \%$.

\section{Conclusion}

If the material prices are analysed (table 1.), it is evident that PLA material with carbon fiber is up to $40 \%$ more expensive than PLA, and PET-G with carbon fiber is up to $28 \%$ more expensive than PET-G. Whether it is profitable to buy and for what kind of applications, it depends on the product itself and the exploitation conditions where it will be applied.

In this study, influence of carbon fibers on tensile properties of PLA and PET-G materials are examined. After analysing the results, it can be concluded that carbon fibers have influence on PLA and PET-G material tensile properties like elastic modulus $(E)$, ultimate tensile strength $\left(\mathrm{R}_{\mathrm{M}}\right)$, yield strength $\left(\mathrm{R}_{02}\right)$, strain $(\varepsilon)$ and toughness:

- Carbon fibers in PLA increased elastic modulus for $50 \%$ and in PET-G for $100 \%$.

- Carbon fibers decrease ultimate tensile strength for $27 \%$ in PLA and for $12 \%$ in PET-G material.

- Carbon fibers decrease yield strength for $21 \%$ in PLA and in PET-G for $7 \%$.

- $\quad$ Carbon fibers decrease strain for $65 \%$ in PLA and in PET-G for $45 \%$.

- Carbon fibers decrease toughness in PLA material for $68 \%$ and in PET-G material for $50 \%$.

Also, from results above its obvious that 3D printing orientation angle has no significant effect on ultimate tensile and yield strength in PLA material, but in CFPLA material, where there were carbon fibers, orientation angle have influence on ultimate tensile and yield strength up to $10 \%$. in PET-G and Carbon-P materials, 3D printing orientation angle have influence on ultimate tensile and yield strength up to $20 \%$.

In order to better describe the properties of the material, in future research, influence of carbon fibers on other material properties (bending, hardness, twisting, etc.) should be examined and analysed. Also, study should use as many specimens as possible, to obtain better and more accurate results.

\section{References}

[1] Gebisa A. W. \& Lemu H. G. (2018). Investigating Effects of Fused-Deposition Modeling (FDM) Processing Parameters on Flexural Properties of ULTEM 9085 Using Designed Experiment, Available from: https://www.mdpi.com/1996-1944/11/4/500 Accessed: 2019-06-07

[2] Cekic A.; Begic-Hajdarevic D.; Muhamedagic K. \& Guzanovic N. (2018). Experimental Investigations of Process Parameters Influence on Dimensional Accuracy and Mechanical Properties of FDM Manufactured Parts, Proceedings of $29^{\text {th }}$ DAAAM International Symposium on Intelligent Manufacturing and Automation, Zadar, ISSN 1726-9679, ISBN 978-3-902734-20-4, Katalinic B. (Ed.), pp.0210-0214, Published by DAAAM International, Vienna, DOI: $10.2507 / 29^{\text {th }}$.daaam.proceedings.030

[3] Polak R.; Sedlacek F. \& Raz K. (2017). Determination of FDM Printer Settings With Regard to Geometrical Accuracy, Proceedings of $28^{\text {th }}$ DAAAM International Symposium on Intelligent Manufacturing and Automation, Zadar, ISSN 1726-9679, ISBN 978-3-902734-11-2, Katalinic B. (Ed.), pp.0561-0566, Published by DAAAM International, Vienna, DOI: 10.2507/28th.daaam.proceedings.079

[4] Pinero Vega D.; Batista Ponce M.; Valerga Pureta A. P.; Vazquez Martinez J. M. \& Fernandez Vidal S. P. (2018). A Comparison of Macro and Microgeometrical Properties of Specimens Made With a FDM Commercial Printer and its Opensource Retrofit Version, Proceedings of $29^{\text {th }}$ DAAAM International Symposium on Intelligent 
Manufacturing and Automation, Zadar, ISSN 1726-9679, ISBN 978-3-902734-20-4, Katalinic B. (Ed.), pp.11081115, Published by DAAAM International, Vienna, DOI: $10.2507 / 29^{\text {th }}$.daaam.proceedings. 158

[5] Papon E. A. \& Haque A. (2018). Tensile Properties, Void Contents, Dispersion and Fracture Behavior of 3D Printed Carbon Nanofiber Reinforced Composite, Reinforced Plastic \& Composites, Vol. 37, No. 6, 2018, pp. 381-395., DOI: https://doi.org/10.1177/0731684417750477

[6] Camargo J. C.; Machado A. R.; Almeida E. C. \& Silva E. F. M. S. (2018). Mechanical Properties of PLA-graphene Filament for FDM 3D Printing, Journal of Advanced Manufacturing Technology, Vol. 170, 2019, pp. 1-21., ISSN: 0268-3768, DOI: https://doi.org/10.1007/s00170-019-03532-5

[7] Farhad M. O.; TahseenFadhil A. \& Hind B. A. (2018). Influence of Process Parameters on Mechanical Properties and Printing Time of FDM PLA Printed Parts Using Design of Experiment. Journal of Engineering Research and Applications, Vol. 8, No. 7, (July 2018) page numbers (65-69), ISSN: 2248-9622

[8] Baich L. (2016). Impact of Infill Design on Mechanical Strength and Production Cost in Material Extrusion Based Additive Manufacturing, Master of Science in Engineering Thesis, Industrial and Systems Engineering Program, Youngstown State University, Youngstown, Ohio - USA

[9] Akhoundi B. \& Behravesh A. H. (2018), Effect of Filling Pattern on the Tensile and Flexural and Mechanical Properties of FDM 3D Printed Products, Experimental Mechanics an International Journal, Vol. 11340, December 2018, ISSN 0014-4851

[10] Jap N. S. F.; Pearce G. M.; Hellier A. K.; Russell N.; Parr W. C. \& Walsh W. R. (2019), The Effect of Raster Orientation on the Static and Fatigue Properties of Filament Deposited ABS polymer, International Journal of Fatigue, Vol. 124., July 2019, 328-337, ISSN 0142-1123

[11] Floor J. (2015). Getting a Grip on the Ultimaker 2 - Tensile Strength of 3D Printed PLA: A Systematic Investigation, Delft University of Technology - Faculty of Industrial Design Engineering \& Ultimaker B.V., 20151215

[12] Xionghao L.; Zhongjin N.; Shuyang B. \& Baiyang Lou. (2018). Preparation and Mechanical Properties of Fiber Reinforced PLA for 3D Printing Materials, Available from: https://iopscience.iop.org/article/10.1088/1757899X/322/2/022012 Accessed: 2019-06-14

[13] El Magri A.; El Mabrouk K.; Vaudreuil S. \& Ebn Touhami M. (2019). Mechanical Properties of CF-reinforced PLA Parts Manufactured by Fused Deposition Modeling, Available from: https://journals.sagepub.com/doi/10.1177/0892705719847244 Accessed: 2019-06-15

[14] Patanwala H. S.; Hong D.; Vora S. R.; Bognet B. \& Anson W. K. M. (2017). The Microstructure and Mechanical Properties of 3D Printed Carbon Nanotube-Polylactic Acid Composites, Available from: https://onlinelibrary.wiley.com/doi/10.1002/pc.24494 Accessed: 2019-06-14

[15] Ipekci A.; Kam M. \& Saruhan H. (2018), Investigation of 3D Printing Occupancy Rates Effect on Mechanical Properties and Surface Roughness of PET-G Material Products, Journal of New Results in Science, Vol. 7, No. 2, May 2018, 1-8, ISSN 1304-7981 